\title{
Multiple Intelligences as a New Paradigm in the Education of Mexico
}

\author{
José G. Vargas Hernández, MBA, Ph.D. \\ Research Professor, member of the National System of Researchers \\ Department of Marketing and International Business \\ University Center for Economic and Administrative Sciences U of G \\ Peripherals Norte 799 Building G-306 \\ Zapopan, Jalisco CP 45,100; Mexico \\ Tel: +52 (33) 37703343 ext 5097
}

E-mail: josevargas@cucea.udg.mx,jgvh0811@yahoo.com,jvargas2006@gmail.com

\author{
Mohammad Reza Noruzi \\ Executive Master Business Administration, EMBA \\ Islamic Azad University, Kaleibar, Iran \\ Faculty of Humanity Sciences, Department of Management and Accounting \\ Young Researchers Club Member, IAU Bonab, Iran \\ Tel: +98- 426-4224915Ｅ-mail:mr.noruzi.pnu@gmail.com
}

Narges Sariolghalam

Applied Mathematics, Faculty of Mathematics

Payam e Noor University of Maragheh, Iran

Tel: +98- 421-2275121Ｅ-mail: n_ghalam@yahoo.com 


\section{Abstract}

The level of education attained by the different people of the world divided between those that only a small segment has achieved the benefits and those who are made great progress by combining a more equitable distribution of opportunities for training and education with high throughput. The less developed economies are not efficient education system to train sufficient human capital with the ability to incorporate knowledge in all sectors of the economy.

This paper aims to study the educational system of Mexico and multiple intelligences in the process of education in Mexican education system too.

Keywords: Higher Education, Mexico, Multiple Intelligences, Educational Policy, Educational Foresight. 


\section{The environment}

The so-called information society and knowledge is a consequence of globalization processes many similarities in trends in higher education globally, such as the universalization of higher education which is expressed in a variety of supply options with different educational plans and curricula. Changing the contents of plans and programs of study should enable Higher Education Institutes, HEIs graduates more opportunities in entering the labor market, considering the requirements of specialization given the scientific and technological advances on the one hand, and the trans-formation. The transformation of the contents of plans and programs of study implies a revision of the principles of educational philosophy and the redesign of academic models and institutional organization, the new grid exit profiles, instructional strategies capable of promoting trans-disciplinarily and complexity of scientific and technological phenomena.

However, rapid scientific advances, especially those in information technology and communications coupled with the increasing economic globalization processes, they need to review and reconsider these assumptions as a requirement of a state policy on public higher education, science and technology, a structural perspective and long-term, if one wants to answer the growing demands of Mexican society of the XXI Century. The evolving role of the state involves re-engineering processes to design new roles in education, research and technological development. The Mexican state should continue to keep the active regulation of the IES by strengthening market mechanisms and the promotion of linking the company to stimulate academic and scientific output.

Herrera (2002) explained that the urgency of institutional transformation in higher education lies in the convergence of forces such as the international trend determined by the impact of globalization and scientific-technological revolution of the late twentieth century, the approach national education policies that are very receptive to the recommendations of multilateral agencies seeking process, in most cases which cause reforms leading to improved quality, coverage and relevance within the traditional, disciplinary, bureaucratic and hierarchical in our country.

Institutional change will bring about change in the paradigm of the educational model in a way which involves the questioning of the societal model in which it is based and leading universities to other ways of thinking, organizing, producing and transmitting knowledge (Lanz, 2003).

NUIES (1999) made the diagnosis of the problems of higher education in Mexico in a prospective for 2020 with a proposal for immediate action to boost higher education system In terms of national and regional development and the role of government, the scenario of 2020 is a model for consultation and coordination with a flexible and decentralized state system of innovation and interaction between firms, markets, governments and universities.

Governments must continue to ensure compliance of the right to higher education and taking responsibility for its financing. The scenario of the political system that is expected to be capable of democratic governance and a broad social policy systematically considers the size 
of the economic and social inequality in Mexico. Inequality in access to higher education is still a case pending, especially in the territorial distribution of higher education opportunities. You have to make substantial progress regarding the new responsibilities in education and research in the state and individuals in the transformation of higher education.

In the demographic component, CONAPO projections indicate that population growth will diminish over the next five decades: by 2010 the population would range from 111.3 million inhabitants and 116; for 2020 at 119.7 to 130.5, for 2030 of 124.4 to 142.2 and for 2050 from 122 to 152.2 (p. 15). The applicant population growth of higher education, from 15 to 64, increases to reach 80.8 million by 2031 and then dropped gradually. For the specific age group of higher education (16 to 22 years) is projected to grow until 2010 to fall from 2025, which implies that we should meet with the creation of new universities. An urban sprawl will have adverse consequences in HEIs. The population dynamics underpinning the challenge of covering higher education hinders the improvement of quality.

\section{Governance in education}

The creation of forms of government and organization of HEIs while focusing on economic efficiency, more effectively in social development will remain a major challenge especially because new strategies are required for the generation and application of knowledge when changing the paradigms of scientific and technological higher education. New forms of government and legislation of the IES must be consistent with the challenges of economic globalization processes and the revolution in information technology and communications.

Also, decision-making processes must be open to more democratic processes, by strengthening flatter structures, use of information and communication technologies on end and behavior subject to processes of transparency and accountability. The diversification of institutional structures is manifested in a variety of organizational forms to provide care through programs and curricula to the needs of education, science and technology. The decision-making processes should be transparent, providing horizontal and inclusive openness to all stakeholders, but especially teachers, researchers and students, the main players in the processes of teaching and learning.

The opening must allow new ways of choosing the government of the IES, in such a way that promotes greater participation in all academic and scientific community. It proposes the creation of spaces for the academic exercise of democracy under the principle of equal relationship-academic students (teachers and researchers) - management-government.

The search for alternatives leads to the construction of innovative new educational spaces that allow the open expression, flexible, interdisciplinary and self-regulated academic life of the multiplicity of actors. The autonomy of universities from a wide variety of institutions of higher education, science and technology make relationships more meaningful inter-institutional coordination to exploit comparative advantages and areas of excellence for sharing resources, joint efforts and programs through strategic alliances.

Advances in strategic alliances and international agency programs to complement the infrastructure for teaching, research and graduate, so that it allows for greater student and 
academic mobility of teachers and researchers. Academic life must be sustained in horizontal relationships with the administrative part. In the future there should be more concerned because the forms of governance of HEIs, their structures are representative of the main actors in the process of teaching and learning, research and general involvement in the decision-making processes of the major beneficiaries of community, business and civil society.

The creation and maintenance of state networks, regional, national and international help to make more efficient use of resources to provide innovative educational services of high quality, coverage and relevance. The quality of education is understood in a multidimensional way to understand the quality of teaching, management, academic programs, students, etc.. The National Development Plan (2006-2012) meant by quality of the education system, a multidimensional variable that combines access, equity, relevance and educational outcomes', the plan sets out strategies for cross-sectoral and strengthen the processes of learning assessment, teacher performance and school management.

Substantially improve the quality of higher education basing themselves on the improvement of graduate teachers, and in exercise of the National Assessment and Accreditation. It is intended that by 2020 the system is consolidated national planning and evaluation, accreditation and quality assurance in higher education.

\section{Multiple Intelligences Based Learning System, the Necessity of the Future Education in Mexico}

\section{What is Intelligence?}

There are also two major consensus definitions of intelligence. First, from "Intelligence: Knowns and Unknowns" a report of a task force convened by the American Psychological Association (1996; p.77):

Individuals differ from one another in their ability to understand complex ideas, to adapt effectively to the environment, to learn from experience, to engage in various forms of reasoning, to overcome obstacles by taking taught. Although these individual differences can be substantial, they are never entirely consistent: a given person's intellectual performance will vary on different occasions, in different domains, as judged by different criteria. Concepts of "intelligence" are attempts to clarify and organize this complex set of phenomena.

A second definition of intelligence comes from "Mainstream Science on Intelligence", which was signed by 52 intelligence researchers in 1994:

a very general mental capability that, among other things, involves the ability to reason, plan, solve problems, comprehend complex ideas, learn quickly and learn from experience. It is not merely book learning, a narrow academic skill, or test-taking smarts. Rather, it reflects a broader and deeper capability for comprehending our surroundings- "catching on", "making sense" of things, or "figuring out" what to do (Moafian, 2008).

Of course, there is nothing wrong with any of these definitions or uses of the word intelligence. The problem is that none of them seems to explain it completely. It is difficult to state a specific 
definition for intelligence since it has been used as such a general label for so many talents, abilities and aptitudes.

\section{Background of Multiple Intelligences}

There are different approaches to understanding intelligence. The psychometric view is the most traditional one. According to this approach, there is a single intelligence, which is often called general intelligence. Every individual is born with a certain intelligence or potential intelligence, which is difficult to be changed. Psychologists can assess one's intelligence (IQ) by means of short-answer tests and other purer measures such as the time it takes to react to a flashing light or the presence of a certain pattern of brain waves (Gardner, 2004). But the traditional IQ tests did not satisfy the researchers, so they developed a number of alternative theories, all of which suggest that intelligence is the result of a number of independent abilities that uniquely contribute to human performance. These theories suggest that rather than being fixed, unitary, and predetermined, intelligence is modifiable, multi-faceted, and capable of development (Gardner, 1993; Sternberg, 1986; Vygotsky, 1978; Yekovich, 1994; cited in Campbell, 2000, p. 8). Some of these theories have been summarized in the following paragraphs:

Robert Sternberg in his triarchic view of intelligence proposed three types of intelligence: 1) Componential Intelligence (analytical thinking): academic abilities to compare, evaluate and solve problems. 2) Experiential Intelligence (creativity and insight): the ability to invent, discover and theorize. 3) Practical Intelligence (street smarts): contextual abilities to adapt to the environment (Brown, 2000; Chastain, 1988). This theory of intelligence claims that intelligent behavior stems from a balance between analytical, creative and practical abilities and that these abilities function collectively to allow individuals to achieve success within particular socio-cultural contexts (Sternberg, 1988).

Gardner, in his MI theory, proposes that human intelligence has multiple dimensions that must be acknowledged and developed in education. He notes that traditional IQ or intelligence tests (such as Stanford-Binet test) measure only logic and language, but there are other equally important types of intelligence (Richrads \& Rodgers, 2001).

According to Gardner (1993), intelligence is a biopsychological potential. Intelligences cannot be seen or counted. They are used to process information and can be activated in a cultural setting to solve problems or create products that are of value in a culture. These potentials' activation depends upon the values of a particular culture, the opportunities available in that culture, and the personal decisions made by individuals and/or their families, schoolmasters, and others (Moafian, 2008).

\section{Multiple Intelligences Theory}

Gardner's MI theory posits that human beings possess at least eight intelligences, to a greater or lesser extent. They are as follow (Armstrong, 2009, pp.6-7):

Once this broader and more pragmatic perspective was taken, the concept of intelligence began to lose its mystique and became a functional concept that could be seen working in people's 
lives in a variety of ways. Gardner provided a means of mapping the broad range of abilities that humans possess by grouping their capabilities into the following eight comprehensive categories or "intelligences":

Linguistic: The capacity to use words effectively, whether orally (e.g., as a storyteller, orator, or politician) or in writing (e.g., as a poet, playwright, editor, or journalist). This intelligence includes the ability to manipulate the syntax or structure of language, the phonology or sounds of language, the semantics or meanings of language, and the pragmatic dimensions or practical uses of language. Some of these uses include rhetoric (using language to convince others to take a specific course of action), mnemonics (using language to remember information), explanation (using language to inform), and metalanguage (using language to talk about itself).

Logical-mathematical: The capacity to use numbers effectively (e.g., as a mathematician, tax accountant, or statistician) and to reason well (e.g., as a scientist, computer programmer, or logician). This intelligence includes sensitivity to logical patterns and relationships, statements and propositions (if-then, cause-effect), functions, and other related abstractions. The kinds of processes used in the service of logical-mathematical intelligence include categorization, classification, inference, generalization, calculation, and hypothesis testing.

Spatial: The ability to perceive the visual-spatial world accurately (e.g., as a hunter, scout, or guide) and to perform transformations upon those perceptions (e.g., as an interior decorator, architect, artist, or inventor). This intelligence involves sensitivity to color, line, shape, form, space, and the relationships that exist between these elements. It includes the capacity to visualize, to graphically represent visual or spatial ideas, and to orient oneself appropriately in a spatial matrix.

Bodily-kinesthetic: Expertise in using one's whole body to express ideas and feelings (e.g., as an actor, a mime, an athlete, or a dancer) and facility in using one's hands to produce or transform things (e.g., as a craftsperson, sculptor, mechanic, or surgeon). This intelligence includes specific physical skills such as coordination, balance, dexterity, strength, flexibility, and speed, as well as proprioceptive, tactile, and haptic capacities.

Musical: The capacity to perceive (e.g., as a music aficionado), discriminate (e.g., as a music critic), transform (e.g., as a composer), and express (e.g., as a performer) musical forms. This intelligence includes sensitivity to the rhythm, pitch or melody, and timbre or tone color of a musical piece. One can have a figural or "top-down" understanding of music (global, intuitive), a formal or "bottom-up" understanding (analytic, technical), or both.

Interpersonal: The ability to perceive and make distinctions in the moods, intentions, motivations, and feelings of other people. This can include sensitivity to facial expressions, voice, and gestures; the capacity for discriminating among many different kinds of interpersonal cues; and the ability to respond effectively to those cues in some pragmatic way (e.g., to influence a group of people to follow a certain line of action).

Intrapersonal: Self-knowledge and the ability to act adaptively on the basis of that knowledge. This intelligence includes having an accurate picture of oneself (one's strengths and 
limitations); awareness of inner moods, intentions, motivations, temperaments, and desires; and the capacity for self-discipline, self-understanding, and self-esteem.

Naturalist: Expertise in the recognition and classification of the numerous species - the flora and fauna-of an individual's environment. This also includes sensitivity to other natural phenomena (e.g., cloud formations, mountains, etc.) and, in the case of those growing up in an urban environment, the capacity to discriminate among inanimate objects such as cars, sneakers, and CD covers.

Daniel Golman introduced the concept of Emotional Intelligence (EI). He claimed that efficient mental or cognitive processing is necessary for controlling even a handful of core emotions- anger, fear, enjoyment, love, disgust, and others. More to the point, Golaman compared the rational mind with the emotional mind. In comparing the rational mind with the emotional mind, Golman argued that the emotional mind is far quicker and acts without even pausing to consider what it is doing. He stated that the quickness of emotional mind prevents a deliberate, analytic reflection that is the sign of the thinking mind (Golman, 1995).

The theoretical framework of the present study is based on Gardner's MI theory. This theory has a positive and expansive view towards intelligence (Campbell, 2000).

\section{How to Teach or Learn Anything 8 Different Ways}

One of the most remarkable features of the theory of multiple intelligences is how it provides eight different potential pathways to learning. If a teacher is having difficulty reaching a student in the more traditional linguistic or logical ways of instruction, the theory of multiple intelligences suggests several other ways in which the material might be presented to facilitate effective learning. Whether you are a kindergarten teacher, a graduate school instructor, or an adult learner seeking better ways of pursuing self-study on any subject of interest, the same basic guidelines apply. How you might connect it with (http://www.thomasarmstrong.com/multiple_intelligences.htm):

o words (linguistic intelligence)

o numbers or logic (logical-mathematical intelligence)

o pictures (spatial intelligence)

o music (musical intelligence)

o self-reflection (intrapersonal intelligence)

o a physical experience (bodily-kinesthetic intelligence)

o a social experience (interpersonal intelligence), and/or

o An experience in the natural world. (naturalist intelligence)

\section{Developing MI}

Whether intelligence can develop depends upon three main factors (Armstrong, 2009, p.27): 
1. Biological endowment-including hereditary or genetic factors and insults or injuries to the brain before, during, and after birth

2. Personal life history-including experiences with parents, teachers, peers, friends, and others who awaken intelligences, keep them from developing, or actively repress them

3. Cultural and historical background-including the time and place in which you were born and raised and the nature and state of cultural or historical developments in different domains we can see the interaction of these factors in the life of Wolfgang Amadeus Mozart.

\section{Strategies for Managing Individual Behaviors}

\begin{tabular}{|c|c|c|c|}
\hline Intelligence & Aggressive Student & Withdrawn Student & Hyperactive Student \\
\hline Linguistic & $\begin{array}{l}\text { Bibliotherapy on theme of } \\
\text { anger management }\end{array}$ & $\begin{array}{l}\text { Taking up debate, oratory, } \\
\text { or storytelling }\end{array}$ & $\begin{array}{l}\text { Books on theme of } \\
\text { hyperactivity (e.g., The } \\
\text { Boy Who Burned Too } \\
\text { Brightly) }\end{array}$ \\
\hline $\begin{array}{l}\text { Logical- } \\
\text { Mathematical }\end{array}$ & $\begin{array}{l}\text { Dreikurs's logical- } \\
\text { consequences system }\end{array}$ & $\begin{array}{l}\text { Interactive computer } \\
\text { network, chess club }\end{array}$ & $\begin{array}{l}\text { Quantification of time } \\
\text { on task }\end{array}$ \\
\hline Spatial & $\begin{array}{l}\text { Visualizing ways of } \\
\text { managing conflict }\end{array}$ & $\begin{array}{l}\text { Movies on theme of } \\
\text { withdrawn child who } \\
\text { meets a friend }\end{array}$ & $\begin{array}{l}\text { Video games that help } \\
\text { develop focus and control } \\
\text { (neurofeedback) }\end{array}$ \\
\hline $\begin{array}{l}\text { Bodily- } \\
\text { Kinesthetic }\end{array}$ & $\begin{array}{l}\text { Role-play aggressive } \\
\text { behavior and try out } \\
\text { alternatives }\end{array}$ & $\begin{array}{l}\text { Pairing with trusted } \\
\text { person for walks, sports, } \\
\text { games }\end{array}$ & $\begin{array}{l}\text { Progressive relaxation, } \\
\text { yoga, hands-on learning, } \\
\text { strenuous exercise }\end{array}$ \\
\hline Musical & $\begin{array}{l}\text { Songs promoting social } \\
\text { skills }\end{array}$ & $\begin{array}{l}\text { Discography encouraging } \\
\text { connection with others }\end{array}$ & $\begin{array}{l}\text { Stimulating music } \\
\text { ("Musical Ritalin") }\end{array}$ \\
\hline Interpersonal & $\begin{array}{l}\text { Taking group class in } \\
\text { martial arts }\end{array}$ & Group counseling & $\begin{array}{l}\text { Leadership role in } \\
\text { cooperative learning group }\end{array}$ \\
\hline Intrapersonal & Time out, contracting & $\begin{array}{l}\text { One-to-one counseling/ } \\
\text { psychotherapy }\end{array}$ & Focusing exercises \\
\hline Naturalist & $\begin{array}{l}\text { Identifying with an animal } \\
\text { that can then learn how to } \\
\text { "tame itself" }\end{array}$ & $\begin{array}{l}\text { Introspective book about } \\
\text { nature involving friendship } \\
\text { (e.g., The Secret Garden) }\end{array}$ & Time in nature \\
\hline
\end{tabular}

Armstrong, 2009, pp.117-118

\section{The politics of higher education, science and technology}

The lines of education policy have a tendency to continuity and deepening of the National Development Plan (NDP) 2007-2012, which proposes an education based on educational change, with little input to overcome the limitations of the national education system 
( Observatorio Ciudadano de la Educación, 2007b). Under the concept of human development, the NDP aims to secure the Mexican meeting the education needs (NDP 200-2012:23) and recognized as a proposal for Project Mexico 2030, achieve a quality education with value formation and capabilities. The promotion of sustainable human development is guided by a focus on improving education and training as essential elements.

The processes of institutional transformation of higher education in Mexico involving powerful interest groups at local and federal governments in the formulation and implementation of strategies, as has been shown that each institution is a different case.

The government plans set attempting to change the higher education system have different characteristics of implementation, considering the willingness of the actors and autonomy of public and private institutions. One of the main trends in higher education systems is the quantitative expansion to allow access to all social groups in the regions. In the near future, the Mexican educational system must end the gulfs of inequality in the geographical distribution.

Expand the options available to the inhabitants of certain areas, whether you want to benefit the largely rural and indigenous people. The transformation of education is one of the challenges of equal opportunities in program development proposal of the NDP (2006-2012). The priorities are outlined in the general expansion of system to ensure educational opportunities for all people, removing economic exclusion, to computerize the national educational system, coordinate and decentralize and support for teaching through resources and training (Observatorio Ciudadano de la Education, 2007: 34).

Strategies for Education are located on the axes of the competitive economy and generate employment, equal opportunities and environmental sustainability. In the line of "high productivity growth, the policies suggested linking education and scientific and technological development with productivity, which paid little progress to increase as they have been limited investment by both the public and the private. In the last six years (2000-2006) was decreasing trend in the proportion of expenditure and GDP for the development of research and technology.

So far, the contributions of private initiative have been irrelevant, if compared with other countries where heavy contributions made by the main beneficiaries of research in science and technology. The private higher education must remain flexible to adapt to future conditions of changes in governance among regulatory agencies in the markets - the company - and three levels of government. The role of IES historically claimed to be the cultural bulwark in modern societies is becoming one more of the education service providers to serve the laws of the free market.

In the private sector are contained Higher education institutions serving elite students from high income levels and high levels of academic quality on one hand and on the other, those universities that receive surplus unmet demand, which do not necessarily reach the average quality of the IES and which are also characterized by modest tuition fees. Perhaps the most important step which should give private education is to achieve territorial decentralization to 
increase its responsiveness to communities, villages and municipalities. The strong market orientations sebe not be cause for neglect of activities that investment by sources in its structure, not an immediate return (Altbch, 2002).

Among the assumptions of public higher education in Mexico, it is assumed as one of the state's social commitments with the characteristics of free, universal and secular. It is the responsibility of Mexican society demand that the State fulfills its functions to a viable long-term dimension, the higher education project to promote and achieve the conclusion of all efforts in a comprehensive and inclusive agreement of all sectors social.

The Mexican state will continue to ensure effective and making the social right of access to public education to all citizens who choose to continue on some of the institutions of higher education, science and technology, either public or private.

The social projection of present and future development of the IES should be guided by educational policies more consistent with the responsibilities arising from the economic reality and social policy of our people, ie educational policy with a full orientation of social policy. The XXI century Mexican society deposits in the institutions promoting knowledge certain responsibilities and expectations to which higher education institutions (HEIs), universities and technology cannot support others (Casanova Cardiel, 2007:36)

To achieve this, in the coming years, envisions a national project of structural reform of higher education, science and technology, who led the state with strong involvement of social and productive sectors. This project should be able to propel a new future national development model, able to consider the asymmetries and inequalities that exist in different economic, social and cultural rights which provide higher education, science and technology.

Achieving greater equity in income distribution in a country like Mexico where there is great inequality of income, represents a challenge that is related to economic growth and therefore the growth of educational provision to extend coverage opportunities. The national education project should ensure educational equity through mechanisms designed for educational federalism, but also must balance the equity with the involvement of school culture to the cultures of communities so as to strengthen intercultural education. The promotion of educational equity is to address target populations through the implementation of social policy cross-cutting strategies to support those most in need (Observatorio Ciudadano de la Educación, 2007).

The new education project is closely linked to the project of nation we want for Mexico. The new education project should be the result of a government policy sustained in the quality and competitiveness of the Mexican education system

The politics of higher education, science and technology needs to be made comprehensive and coordinated manner to have a reference point and aim the improvement of national education. A State policy on higher education, science and technology should promote the modernization 
of the institutions responsible for providing this service and strengthening the quality, transparency, accountability.

The policies of higher education, science and technology should be set with the aim of substantially increasing the coverage of higher education open to a broader scope of care that exceeds $50 \%$ of the total youth population in such a way as to make more reality one of the great principles of the Mexican state. This is feasible considering the population window of opportunity due to the trend in low birth already present in the last decade.

\section{Draft Institution of Higher Education, science and technology to future}

The IES must be a university or a technologist with a project that goes beyond out into all areas of human development. The institutional complexity of the national education system is expressed in respect for the autonomy of universities makes it difficult to agreements to supplement resources.

Therefore, it requires institutional reform and consolidation on a framework that facilitates coordination and complementation rational and equitable use of resources and efforts of institutions of higher education, science and technology to achieve higher levels of development that meets the profiles regional. The discussion will focus on designing a model-oriented university more utilitarian sense of teaching and research in the design of a university model with a utopian project of democratic emancipation.

The IES implement programs for improvement in the quantity and quality of its infrastructure, environmental conditions and academic programs, with a parallel drive to stock assessment indicators. The criteria of quality, certification and accreditation of academic programs will be established by consolidated academic bodies in institutions of higher education, science and technology.The academic quality of programs of higher education, science and technology, is the condition to increase the certification processes and to guide the quantitative growth.

Institutional transformation has to further innovations in the academic model that takes into account the emergence of processes of economic globalization, scientific and technological changes are more advanced in the different areas of knowledge, the advancement of communication technologies and information.

The ANUIES (1999) recommends following the strategies of planning and coordination to ensure the integration of higher education system. In 2020, the IES of Mexico will form a higher education system able to train professionals and senior researchers, generate and apply knowledge, expand and preserve culture. All these tasks are performed with quality, relevance, equity and amount comparable to international standards.

The strategies to implement institutional change in higher education should consider the many variables involved. Among the variables involved are highlighted in national educational policies and the maturity and bargaining power of institutional actors. 


\section{Knowledge generation and innovation}

The training of the future should focus more attention on teaching the totals. Vocational training to become a promoter of human values but to discourage selfish individualism, which encourages respect for life in society, without neglecting the social solidarity, the preservation of nature and the environment.

The educational model must recognize the centrality of the student and the recognition of individual differences in learning processes and with the support of teachers to organize and share their experiences through academic processes. Achieve the consolidation of academic bodies and areas of knowledge consolidated and made academic innovation activities of generation, and application of knowledge to solve the problems of economic and social environment.

The learning system of the new model of higher education, science and technology should be supported, though not necessarily revolve around intensive use of technology and information communication technologies (ICTs).

The characteristics of the profiles of the graduates will be certified by external bodies. Professional certification and institutional accreditation to international standards of professional practice will promote a culture of planning and collegial self-evaluation.

The quantitative scenarios registration, titling, coverage and general issues in higher education by 2020, are determined by the conditions of inequality, inequity and social injustice. It requires an expansion of the education system as well as government initiatives and other sectors of the economy and society, to encourage recruitment of social demand and expand the coverage of the system.

You have to argue that the effort should focus on making the curriculum change, his times, teaching methods and techniques, the change must be addressed essentially the same content of the disciplines.

The ANUIES (1999) recommended in the years to achieve an open system of higher education against a closed, institutional networking, the use of information technology and communication for the formation of the virtual university, the grant legal personality to the rating agencies, and accrediting certifiers.

\section{Linking}

Linking State-IES-business-society is a prerequisite to complement the efforts of attention to the demand for higher education services posed by population growth, so that they can create and professions necessary to develop economic reality, social and political life. Linking education, science and technology for productive and social sectors will be strengthened

The development of research projects, technology transfer and technological research must be a shared responsibility of mixed financial funds from the agents and actors who benefit most, 
businesses, state and Mexican society. It must encourage and increase the levels of research and graduate training through research, teaching, disseminator of culture, with capacity to encourage deep learning, knowledge generation, problem solving in various scientific and technological fields of application, provided in current educational policies.

A proposal to encourage private sector participation is to create programs where higher education services to employers offering benefits to attract investment. The dynamism of the private sector could ease the pressure of rising demand, but with dissimilar levels and very questionable in quality of service provided.

Leveraging the advantages of an information society and knowledge, the international mobility of academics, researchers and students will enhance the exchange of experiences, knowledge, skills, values and attitudes that will expand the horizons of vocational training. It is also important to promote programs linkage with multinational and global companies, not only to replenish the plans and programs of study but also to facilitate the employment of graduate immersion.

Institutional innovations to support the substantive functions of HEIs require better structures to expand services to business centers, business incubation programs, etc.Not to mention the link with social and political sectors through programs such as ciberbolsas work, support groups and marginalized social exclusion, participation in specific projects of the three levels of government to promote regional and economic development, etc. .

\section{Finance}

The National Development Plan (2006-2012) is very brief to identify possible sources of funding and resources needed for education, research and technological innovation. Due to the high costs of higher education and scientific research and technological quality, new financing schemes will have serious repercussions on inter-relationships between HEIs and government authorities. These impacts would be reflected in the reduction of subsidies and budget allocations, in a more efficient exercise of spending and available resources.

The improvement in the rationale for allocating the financial resources to the various institutions of public education is crucial to abandon old practices articulated in international negotiations institutional political factors - rather than partisan-centered rationality academic results. Therefore, in the coming years is to increase the quality of the processes of transparency and accountability of the substantive responsibilities of HEIs.

The IES must take concrete actions to increase transparency and accountability in the exercise and operation of public financial resources in a cohesive way with their university autonomy and other components of higher education systems in such a way that promotes collaboration complementarity institutional. The State should consider the investment in higher education and scientific research as social investment. 
Increasing budgetary constraints financially pressuring higher education institutions in Mexico have impacted strongly on delivering quality education services in the public sector. The heavy tax burden that higher education represents for the Mexican state that can not meet all the expectations of scientific and technological training of Mexicans, has led to social transfer this responsibility to the private sector, not without difficulties for the huge infrastructure investments needed to provide educational services efficiently and effectively.

The quantitative growth of the private sector in education and research will result in higher recruitment of upper-class students by offering a higher leadership position, despite the heterogeneity. Many HEIs will travel paths for the conversion of public to private universities through market mechanisms their products, such as graduates, knowledge and values.

Higher education requires a sustained effort to manage financial resources to meet the responsibilities for training, preservation of identity and values of culture, science and technology, knowledge generation, technological innovation, technology transfer etc. Transfer the responsibilities of financial contribution to private sector only partly resolve the complex problem because it limits opportunities for social mobility to those who need it because they can pay their training, so it is imperative that the State assume financial responsibility under a perspective long range to strengthen higher education in highly competitive sectors of society who lack the resources to do it by themselves.

Although one must strive to advance the state responsibility for higher education to meet the educational demand in the next 13 years is necessary that educational services are expressed in terms of provision and demand for education on a regulated market, resources and educational inputs to shore up a knowledge society and information. The knowledge society and the adoption of the paradigm of lifelong learning and lifelong education are assumptions regarding the context of UNESCO.

The implementation of public investment in higher education is a response to the needs of most Mexicans who do not have the opportunity to access higher education in order that all public and private HEIs have the educational infrastructure and academic plant best to provide quality education. To achieve this, are required to implement new ways of financing public higher education to respond adequately in coverage, relevance and quality. On the other hand increase the responsible social participation in education spending but also to become social auditors, as mechanisms to enforce the transparency and accountability that direct management and academics (teachers and researchers) for a correct application of financial resources.

The management of financial resources will become significant in the coming years which will require a greater deal of creativity To eke out scarce resources, and to new programs such as exploring linkages with other universities and foundations that have bags of funding for specific projects vocational training, creation of scientific and technological knowledge, technological innovation programs, technology transfer, support for disadvantaged groups to access to educational opportunities, etc.. 
In the coming years is to increase the management capacity to raise funds for financing, for example, by offering teaching activities, research, innovation, development and linkage to services can be classified as multiplier effects spill benefits to the students and researchers. One would expect that in the Mexico of the future, private initiative will increase their contributions, which would make them less dependent on progress in this area are conducted in more advanced countries.

The scarcity of financial resources and the urgent need for financing the activities of higher education, especially with regard to infrastructure and educational equipment will help us to generate resources from other sources such as the creation of trusts, institutional credit and income for themselves towards sale of services.

\section{Comprehensive assessment of the educational process}

The current National Development Plan (2006-2012) proposes the creation of the National System of Educational Evaluation in the middle and higher education and teacher performance measurement. In higher education, science and technology is a priority in the years to establish a comprehensive evaluation system of education is more focused on the evaluation of the entire educational process including the results.

This system should evaluate the performance of all actors involved in educational processes, including the State, community, education officials, teachers and researchers, parents, support institutions, students, etc. Similarly, the comprehensive evaluation system of the educational process should evaluate the institutions, infrastructure, financial resources and materials, resources and teaching aids, etc..

To achieve greater resource efficiency is necessary to implement assessment systems, accreditation and accountability for the application of resources. It requires policies, strategies, norms and performance indicators of academic quality and attention to environmental demands and the labor market. It is also important to disseminate the results of the evaluations, ensuring feedback to those involved in educational processes to establish appropriate remedial measures.

\section{Needs Action}

The remaining tasks proposed by De la Fuente (2007) to advance the knowledge society are: Investing in education, research and development, rede form a world-class university, raising the academic standards of the economically active population and import knowledge and not only export

The training of the future must be capable of combining pragmatic and empirical knowledge with theoretical and methodological knowledge. The reorganization of knowledge and their inter-disciplinary and interdisciplinary, relationship of curriculum and teaching-learning processes, and so on. Are urgent matters that the transformation of institutional academic management must address? 
Higher education has as its main development challenges of educational content and curriculum plans from transdisciplinarity, complexity and uncertainty, methodological strategies, new forms of organization and government, creating strategic alliances for complementary resources, etc. The processing of HEIs in Mexico will face as a major challenge to respond in a more responsible to the demands of social and productive sectors.

The challenges of higher education is to rethink its role and mission to establish alternative strategies for the future in a framework of sustainable development, peace culture and a global ethic. The challenges of educational reality require cooperation and solidarity as the foundations to avoid marginalization, fragmentation and polarization of knowledge.

Taking a critical discourse about the scope of the functions of the new model under the IES and a focus on market requirements underestimate the social needs of the Mexican state.

\section{References}

Armstrong, T. (2000). Multiple intelligences in the classroom. . Alexandria, VA,USA: Association for Supervision. Retrieved July 18, 2007 [Online] Available: http://site.ebrary.com/lib/modarres/Doc?id=10044795\&page=1

Armstrong, T. (2009). Multiple intelligences in the classroom. third Edition, Alexandria, Virginia USA,

Altbch, Philip. (2002). Private higher education, UNAM / Group Editorial Porrua, Mexico, 2002.

ANUIES. (1999). the document "Higher Education in the XXI century. Lines strategic development. National Association of Universities and Institutions Higher Education. Mexico.

Brown, H. D. (2000). Principles of language learning and teaching ( $4^{\text {th }}$ ed).San Francisco: Pearson Education.

Campbell, L. M. (2000). The unspoken dialogue: Beliefs about intelligence, students, and instruction held by a sample of teachers familiar with the theory of multiple intelligences. Unpublished doctoral dissertation, The Fielding Institute. United States.

Casanova Cardiel, Hugo. (2007 State responsibility, "Este País, No. 198, 35-38September 2007.

Chastain, K. (1988). Developing second language skills: Theory and practice (3rd ed). United States of America: Harcourt Brace Jovanovich.

De la Fuente, Juan Ramón. (2007). "University and Development", Este País, 197, August 2007, Pages 12-14.

Gardner, H. (2004). A multiplicity of intelligences: In tribute to Professor Luigi Vigno. Retrieved May 2, 2007 [Online] Available: http://www.howardgardner.com/Papers/ documents/T-101\%20A\%20Multiplicity\%20REVISED.pdf

Gardner, H. (1993). Multiple intelligences: The theory in practice. New York: Basic Books. 
Herrera, Alma. (2002). "The change in the nineties: a comparative study of public ten universities in Mexico, "in T. Didrikson, Axel and Alma Henderson (Ed.), The Transformation of Mexican University: ten case studies in the transition, Universidad Autonoma de Zacatecas / Grupo Editorial Porrua, Mexico, 2002. p. 9-10.

Lanz, Rigoberto. (2003). "What do you mean" university reform?: What people want they want reform, "mimeo, Caracas, March, 2003.

Llorens Baez, Luis. "Feasibility of a higher education system in Mexico: Comments on the document "Higher Education into the Twenty-First Century.

Moafian, Fatemeh. (2008). the relationship between Iranian EFL teachers multiple intelligence and their success in language teaching a comparative study, Mazandaran University, under supervision of Reza Pishghadam

Observatorio Ciudadano de la Educación. (2007). A new educational model for XXI century Mexico? Education proposed by the SNTE "This Country 198, September 2007, pages 30-34.

Observatorio Ciudadano de la Educación. (2007b). "The" educational transformation" according to the National Development Plan 2007-2012 ", This Country 107, August 2007, Pages 34-39.

Richards, J. C., \& Rodgers, T. S. (2001). Approaches and Methods in Language Teaching $\left(2^{\text {nd }}\right.$ ed). Cambridge: Cambridge University Press.

Sternberg, R. J. (1986). What is intelligence? Norwood, NJ: Ablex.

Sternberg, R. J. (1988). The triarchic mind: A new theory of human intelligence. New York: Viking.

Vygotsky, L. S. (1978). Mind in society: The development of higher psychological Processes. Cambridge, MA: Harvard University Press.

Yekovich, F. R. (1994). Current issues in research on intelligence. Educational Resources Information Center Digest \#385605 